\title{
Psychological Aspects Operating on the Air Traffic Controller in Reintegration into Action After the Accident
}

\section{Daniela Čekanová $^{1 *}$, Žaneta Miženková ${ }^{2}$, Ľubomír Fábry², Róbert Rozenberg ${ }^{2}$}

\footnotetext{
${ }^{1}$ Department of Air Transport Management, Faculty of Aeronautics, Technical University of Košice, Košice, Slovak Republic

${ }^{2}$ Department of Flight Training, Faculty of Aeronautics, Technical University of Košice, Košice, Slovak Republic

*Corresponding author: Technical University of Košice, Faculty of Aeronautics, Department of Air Transport Management, Rampová 7, 04112 Košice, Slovak Republic, Email: daniela.cekanova@tuke.sk
}

\begin{abstract}
The aim of the article is to analyze the psychological aspects of an air traffic controller who controls aircraft, communicates with the crew and encounters the incidents of different nature or even accidents. The work of the air traffic controller requires a high level of responsibility and tension which can often lead to stress and trauma. The first part of this article is highlighting the complexity of the profession and passes to the next section, which explains the context of workload, stress and trauma. Long-term stress and traumatic experience of ATC maybe harmful or contribute to early resignation from work. The selection of suitable candidates and their preparation for the profession of air traffic controller is so demanding that their work and psychological aspects require increased attention from the side of the research.
\end{abstract}

Keywords

Accident - Air traffic controller - Cope with stress - Incident - Return to work - Stress - Trauma

\section{Introduction}

The profession of air traffic controller (ATC) is a highly demanding job that requires a high level of responsibility and stress resistance for its nature and complexity of work performed. Similarly, as the aircraft crew, air traffic controllers also belong to the aviation professionals who face high stress or trauma, depending on the experience [1]. ATC, often at larger airports can daily see, hear or try to assume a dangerous situation, possible conflicts, struggle with uncertainty about the accuracy of the information sent or heard [2]. ATC is aware of the responsibility for the lives of people in the aircraft which appear as only small dots on the radar screen. Extremely demanding on the ATC psyche are lost aircraft, accidents, collision, dangerous rapprochement, and failure of aircraft in flight, high jacking, dangerous substances, bomb scare onboard and other misfortunes $[3,4,5]$. 
The aim of this paper is focused on the published knowledge about the psychological aspects of air traffic controllers, symptoms of stress and trauma that air traffic controllers can gain after incidents or accidents they have witnessed. Finally it provides suggestions to help the ATC cope with stress and return back to work after without negative feelings and selfblame.

\section{The psychological impact on the ATC after a critical incident}

Thomas Morin, who worked 23 years in Boston as the ATC and was on duty during 11 September. In his submissions he confirms that it is not easy to be a witness of a critical incident because an air traffic controller experiences the visual and auditory situation. ATC can see on the radar what is happening and hears a pilot who explains the situation at a given frequency [6]. He lives this event very intensely and he feels himself as a part of it, precisely because he talked to the pilot of an aircraft when it departed [7].

The task of ATC, based on different sources of information (radar, flight strips, communication with the pilot), is to control aircraft dynamically in a limited time range, they must diagnose risky separations between the aircraft and resolve potential conflicts. Consequently, they must perceive, understand and predict various characteristics of aircraft and they constantly create a new transport situation [8]. ATC must be able to assume future cognitive activity in the current and rapidly changing situation, which ATC express as air situation - situational awareness, mental representation of current and future traffic conditions. ATC with verbal messages must identify potential conflicts between aircraft, levels of which are characterized by increasing restrictions and specifying the problem space [6]. These steps are:

- observation of the general situation

- analyzing the parameters of the selected aircraft

- creating the presumption.

In the first step, the operator monitors the overall situation in order to gain a quick overview of transport. The aim is to select the strategy for tracking on radar. Experienced ATC divides the aircraft subject to certain signals (vertical movement, distance) in two groups:

- those which require priority treatment to avoid subsequent conflict;

- those that have at the moment safe separations.

The initial steps in solving disruption and conflict can be described in accordance with Rasmusen stages (defining the task, the creation of a process and execution).

\subsection{Cognitive processes and situational awareness}

The ATC cognitive activities involve a number of specific tasks that are a part of the Geneva Convention.
Table 1. Three different levels of processes.

\begin{tabular}{ll}
\hline & - updating mental ideas \\
Level 1 & - maintaining situational awareness \\
& - control \\
& - conflict resolution \\
& - providing information \\
& - monition of a work position \\
Level 2 & - traffic control \\
& - responding to requests and assisting \\
& pilots conflict \\
& - resolution \\
\hline \multirow{2}{*}{ Level 3 } & - coordinating of all activities \\
& - changing of points for attention
\end{tabular}

There is increasing number of publications that deal with cognitive processes and situational awareness. EUROCONTROL used to display cognitive processes table analyzing the work of the ATC during their service, see Tab. 1.

\subsection{Stress of ATC}

In busy traffic conditions the air traffic controller must be still in suspense and anticipation of the new situation. A large degree of responsibility and the hundreds of lives flying in aircraft, leads to stress experience. The greater or lesser stress exists as a daily part of the workday in this profession.

Currently, stress is defined as an immediate biological, physiological and psychological response to an alarm, mobilization and defence of an individual organism in the form of aggression or threat. It is obviously useful and leads to the choice and implementation of adaptive solutions. It evokes the atmosphere of extraordinary tension. Psychological stress finishes with the release and mental relaxation and exhaustion. Stress is not a pathological phenomenon, but if it is too strong, it may become pathological when acting adversely.

\subsection{Excessive stress}

Excessive stress response occurs when an individual is experiencing event too intensely. There are four main reactions:

- reaction of shock, which is an immediate response to sudden danger in all areas of the psyche;

- reaction of disturbed expression;

- escape panic;

- automatic activity.

These reactions of excessive stress do not enable individuals to behave in a given situation appropriately.

\subsection{Behavioural signs of stress}

Behavioural signs of stress in the performance of professional activities lead to qualitatively and quantitatively less power. There errors and uncertainty in executed tasks are manifested more than usual. Zeiler et al also observed and reported increased use of tobacco, alcohol and drugs, resistance to any 
change and the deterioration of human relations. Regarding the signs of emotional stress, study shows irritability, anxiety and sudden mood changes, as well as despair and depression. Inability to show interest in cooperation with others, resignation, lack of desire to work known as burnout are also signs that are important to monitor. The above-mentioned study involved in $88 \%$ of the ATC of the control stations in Zurich and Geneva. The research results confirm the view of experts that professional work of ATC is admittedly difficult, but does not necessarily lead to increased stress as in any other professional activities with comparable requirements. At high density of air traffic and thus increased workload, ATC tend to do high quality work and give the best results. Usually, low professional satisfaction is reflected here.

As people are different, the ATC also do not have the same approach to stressful situations. Good work conditions and elimination of additional stress in other areas is also important for air traffic controllers as follows.

- Dissatisfaction with the leadership and policies of the company, even two-thirds of ATC do not consider actual performance of work the biggest problem but policies of an employer.

- To control workload is very important.

- A critical threshold, which ATC must not exceed varies and should not be construed as a limit. The results show that a lot of ATC who are in a critical zone (10 to 15\%) suffer from severe symptoms of stress. Moreover, it seems that each of ATC, for shorter or longer period, has reached some state of exhaustion.

- Chronic overtime; complaints about problems with their eyes, irregular working hours.

The ATC need to feel the support and safety ensured by the aviation company and to be a part as they are responsible for the company results. So airlines should consider the following suggestions in cooperation with their employees.

- ATC involved in decision-making;

- ATC training in stress management techniques;

- established tools for observation and identifying people who may jeopardize the work;

- define thresholds of competence;

- take concrete measures to improve working conditions and raise awareness about the importance of health;

- reduction of working hours to 35 / week;

- recovery stay every five years;

- increase in salary as a reward;

- establishment of a joint medical commission;

- courses on the human factor.

\section{Possible measures to reduce the adverse effects of stress and trauma}

Overcoming mental conditions, which occur in ATC after an incident or accident, he witnessed, is much more difficult and the future of his profession is in risk. In order to prevent the early retirement and retreating from work of trained professionals, we must contribute to not only their preparation for prevention of stress and trauma, but also to the subsequent process of air traffic controller's return to work [9].

\section{Preliminary preparation for post-traumatic stress}

Air traffic controllers already in preparation for the profession are required basic knowledge within the scope of human factors on human behavior in various situations of potential human errors and solving problems. From experience we know that not always and not everyone who had stressful or traumatic experience is able to overcome anxiety and return to work [10].

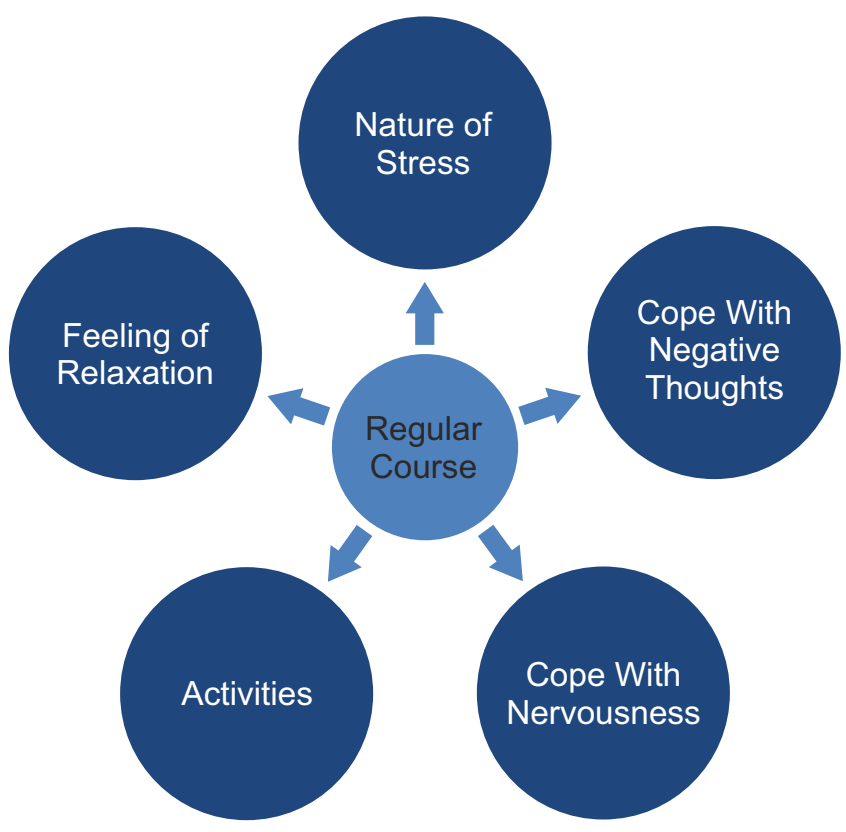

Figure 1. Post traumatic stress desorder course.

\section{Debriefing staff}

Debriefing (discussion after the incident) is a mutual exchange of information on witnessed experience, incident, and accident within the group of people with the same experience. The therapist, psychologist, expert on the human factor are listeners, who have professional skills to lead such a process and help the group to stimulate discussion. The expert also monitors the group members, their reaction to able to judge the degree of traumatic experience and to designate a person who would need additional professional help.

\section{Psychologist needed after the incident}

Psychologists abroad are intensively involved in professions that are stressful, and air traffic controllers' job is stressful, especially in post-traumatic cases. Psychotherapy is a successful procedure for the treatment of trauma.

\section{Working time}

Returning of the ATC back to work and inclusion in the normal duties requires to take into account the length of his working 
time. It's an option that can help him to overcome experienced stress. The psychologist Shields [11] examined the link between long working hours, depression and changes in the behaviour towards their own health (weight changes, smoking, drinking and keeping the socio-economic status, income, education, occupation, etc.). During the two years he examined a sample of adult workers aged 25-54 years who worked 35 hours a week or more. Research has shown that women who worked long hours experienced increased depression. The transition from the standard number of working hours for extended working hours was associated with unhealthy weight gain in men, with an increase in smoking among men and women, and with increased drinking of alcoholic beverages for women.

\section{Support of a manager}

Having a manager who understands the feeling of the staff, and concerns takes seriously and listens to their needs, is a simple but effective means of assistance, support and successful work with a team. This approach has a serious impact on the increased feeling of safety when working with a particular colleague and for restoring mutual trust.

\section{Support of colleagues}

At each company, we have associates and it is not otherwise even in the control tower.Co-workers, colleagues are the ones who are with us at work or right now are free and at home or on vacation. ATC colleagues have the same education and the same responsibilities. Differences can be evident in the age and quantity or quality of experience. Even younger colleagues may have more experience due to the situation dealt with during their work shifts.

\section{Avoid drugs and alcohol}

Drug abuse reduces the person's ability to concentrate, to be devoted to productive work and all the activities of daily life. These people usually suffer from a lack of sleep and rest, thus losing healthy capacity to cope with the traumatic experience and external stressors. Alcohol or drugs may increase emotional paralysis, social isolation, anger and irritability, depression and a sense of panic (hypervigilance).

\section{Expressive writing experience of having a stressful expe- rience}

"Writing about traumatic experiences is associated with shortterm increase in physiological agitation and long-term reduction of health problems“. For example, promising results have been found using email-based writing tasks, web writing, interventions for posttraumatic stress disorder and writing assignments for married couples [12, 13, 14].

Knowledge of these studies is useful for air traffic management. In preparation for the profession, and later in ongoing courses the motivation for writing should be required. The ATC can write a personal diary, to assess whether their fears and negative thoughts and feelings have any relevance to their work and life. Not everyone likes to write, but forms, ways and means one can choose.

\section{Conclusion}

The research abroad pointed to signs of stress and trauma that air traffic controller has encountered in witnessing incident or accident. Based on the knowledge we processed proposals for the assistance of air traffic control to overcome stress and return to work after an incident or accident. We consider the most important regular preparation for possible stressful situations, psychological and physical manifestations and consequences of trauma, treatment options in the team of air traffic controllers under coordination of an expert in human factors and psychology. The team of ATC colleagues is considered a very important factor in the treatment of psychological trauma and has as positive effect on the individual as other proposals in this work. These include debriefing, sports activities, debates, participation of superiors and colleagues. A very important way to prevent the further development of manifestations of stress is to pay sufficient attention to ATC immediately

\section{Acknowledgments}

This research was funded by Ministry of Education, Science, Research and Sport of the Slovak Republic as a part of the project No. ITMS 26220220161 (Research of pilots training methods using flight simulator) co-financed by EU funds.

\section{References}

[1] R. Rozenberg, P. Čekan, and T. Čekanová. Psychological load of flight. In Proceedings of the 9th international scientific conference New Trends in Aviation Development, pages 171-173. Technical University of Košice, 2015.

[2] J. Poprenda, R. Rozenberg, P. Čekan, and T. Čekanová. Ľudský faktor $v$ letectve. Elfa, 2009. ISBN 9788080861070.

${ }^{[3]}$ R. Rozenberg, V. Begera, and L. Melníková. Human factor in formation flying proficiency. In Proceedings of the international scientific conference Aeronautica 2011, pages 11-4. Technical University of Košice, 2011.

[4] V. Socha, J. Schlenker, P. Kalavksy, P. Kutilek, L. Socha, S. Szabo, and P. Smrcka. Effect of the change of flight, navigation and motor data visualization on psychophysiological state of pilots. In 2015 IEEE 13th International Symposium on Applied Machine Intelligence and Informatics (SAMI). Institute of Electrical and Electronics Engineers (IEEE), jan 2015. doi: 10.1109/sami.2015. 7061900 .

[5] M. Regula, V. Socha, P. Kutilek, L. Socha, K. Hana, L. Hanakova, and S. Szabo. Study of heart rate as the main stress indicator in aircraft pilots. In Proceedings of the 16th International Conference on Mechatronics Mechatronika 2014. Institute of Electrical and Electronics 
Engineers (IEEE), dec 2014. doi: 10.1109/mechatronika. 2014.7018334.

[6] V. Begera and R. Rozenberg. Information technologies of air traffic control centres. In Proceedings of the 9th international scientific conference New Trends in Aviation Development, pages 14-17. Technical University of Košice, 2015.

[7] T. Morin. Psychological impact for air traffic controllers post-critical incident, 2010. URL http://owcp.natca.net/Psychological_ Impact_for_Air_Traffic_Controllers_ Post_Critical_Incident.pdf. [Online].

[8] M. Džunda and N. Kotianová. Selected aspects of applying communication technology to air transportation. In Proceedings of International Conference on Computer Science and Information Engineering (CSIE 2015), pages 1-7. DEStech Publications, Inc., 2015.

[9] P. Čekan, P. Korba, and J. Sabo. Human factor in aviation - models eliminating errors. In Transport Means - Proceedings of the International Conference, pages 464-467. Kaunas University of Technology, Jan 2014.

[10] James W. Pennebaker and Sandra K. Beall. Confronting a traumatic event: Toward an understanding of inhibition and disease. Journal of Abnormal Psychology, 95(3): 274-281, 1986. doi: 10.1037/0021-843x.95.3.274.

[11] M. Shields. Long working hours and health. Health Rep, 11(2):33-48, 1999.

[12] Andrea N. Niles, Kate E. Byrne Haltom, Catherine M. Mulvenna, Matthew D. Lieberman, and Annette L. Stanton. Randomized controlled trial of expressive writing for psychological and physical health: the moderating role of emotional expressivity. Anxiety, Stress, \& Coping, 27(1): 1-17, jun 2013. doi: 10.1080/10615806.2013.802308.

[13] C. S. Mackenzie, U. J. Wiprzycka, L. Hasher, and D. Goldstein. Does expressive writing reduce stress and improve health for family caregivers of older adults? The Gerontologist, 47(3):296-306, jun 2007. doi: 10.1093/ geront/47.3.296.

[14] K. A. Baikie. Emotional and physical health benefits of expressive writing. Advances in Psychiatric Treatment, 11(5):338-346, sep 2005. doi: 10.1192/apt.11.5.338. 